\title{
The Study of Bray-Liebhafsky Reaction Over a Wide Range of Temperatures. II. Modelling
}

\author{
R. VÎLCU ${ }^{a} *$, T. DANCIU ${ }^{b}$ and D. BALA ${ }^{a}$ \\ ${ }^{a}$ Physical Chemistry Department, University of Bucharest, 4-12, Elisabeta Boulevard (fost Republicii), 70346 Bucharest, Romania; \\ ${ }^{\mathrm{b}}$ Chemical Engineering Department, University "Politehnica" of Bucharest, 1, Gh. Polizu Street, 78126 Bucharest, Romania
}

(Received 16 December 1998)

\begin{abstract}
From a preview of proposed models a molecular one (involving neither ions nor free radicals) was chosen. The concept of scaled concentrations for intermediates is introduced. A different mechanism (involving Dushman reaction) is proposed for the ignition period.
\end{abstract}

Keywords: Chemical oscillations, Chemical instabilities, Chemical clocks, Chemical chaos, Chemical fluctuations

For over 85 years, people tried to model BrayLiebhafsky (shortly BL) reaction. The very first was Auger in 1911. Since then, many models were proposed. A brief preview of major contributions in this field is shown below. First, let us divide these models in three large categories: molecular, ionic and radicalic ones. All of them try to explain why the decomposition of oxygenated water catalyzed by iodic acid (and iodine):

$$
2 \cdot \mathrm{H}_{2} \mathrm{O}_{2} \stackrel{\mathrm{HIO}_{3} / \mathrm{I}_{2}}{\longrightarrow} 2 \cdot \mathrm{H}_{2} \mathrm{O}+\mathrm{O}_{2}
$$

could exhibit relaxation oscillations in a closed system.

The first step in BL modelling was to consider a redox-type switching between the iodine species based on amphoteric effect of hydrogen peroxide:

$$
\begin{gathered}
2 \cdot \mathrm{HIO}_{3}+5 \cdot \mathrm{H}_{2} \mathrm{O}_{2} \stackrel{1}{\longrightarrow} \mathrm{I}_{2}+6 \cdot \mathrm{H}_{2} \mathrm{O}+5 \cdot \mathrm{O}_{2} \\
\mathrm{I}_{2}+5 \cdot \mathrm{H}_{2} \mathrm{O}_{2} \stackrel{2}{\longrightarrow} 2 \cdot \mathrm{HIO}_{3}+4 \cdot \mathrm{H}_{2} \mathrm{O}
\end{gathered}
$$

but these coupled processes could not explain the observed non-stoichiometric production of oxygen which evolves merely with branch (3) instead of branch (2). To fix this anomaly and according to his experiments (unsaturated organic substances block the $\mathrm{BL}$ reaction), a six steps model involving free radicals was proposed, although RES spectroscopy had not confirmed this assumption (Degn, 1967). Furthermore, the model remained qualitative, without formula for the supposed radicals. Later

\footnotetext{
* Corresponding author.
} 
(Olsen, 1984), this model was extended with an autocatalysis, but these models are of LotkaVolterra type (with conservative center instead of limit cycle).

An important contribution was to consider between the intermediate species the lower oxygenated acids of iodine (i.e., iodous and hypo-iodous) in the famous Brusselator proposed in 1968 by Prigogine and Lefever:

$$
\begin{aligned}
& \mathrm{HIO}_{3}+\mathrm{H}_{2} \mathrm{O}_{2} \stackrel{1}{\longrightarrow} \mathrm{HIO}_{2}+\mathrm{H}_{2} \mathrm{O}+\mathrm{O}_{2} \\
& \mathrm{HIO}_{2}+\mathrm{H}_{2} \mathrm{O}_{2} \stackrel{2}{\longrightarrow} \mathrm{HIO}+\mathrm{H}_{2} \mathrm{O}+\mathrm{O}_{2} \\
& 2 \cdot \mathrm{HIO}_{2}+\mathrm{HIO}+\mathrm{H}_{2} \mathrm{O}_{2} \stackrel{3}{\longrightarrow} 3 \cdot \mathrm{HIO}_{2}+\mathrm{H}_{2} \mathrm{O} \\
& \mathrm{HIO}_{2}+\mathrm{H}_{2} \mathrm{O}_{2} \stackrel{4}{\longrightarrow} \mathrm{HIO}_{3}+\mathrm{H}_{2} \mathrm{O}
\end{aligned}
$$

This model has a limit cycle and gives by summation reaction (1) but also has the major disadvantage of iodine's absence. The third step of Brusselator is so far a cubic autocatalysis, but it seems too complex. Many researchers tried to decompose and refine this step assuming more "elementary" ones.

One way is to consider hypothetical intermediates like iodine dioxide $\left(\mathrm{I}_{2} \mathrm{O}_{2}\right)$. It was introduced by Liebhafsky in a hydrate form (Matsuzaki et al., 1972):

$$
\mathrm{IO}_{3}^{-}+\mathrm{I}^{-}+2 \cdot \mathrm{H}^{+} \longrightarrow \mathrm{H}_{2} \mathrm{I}_{2} \mathrm{O}_{3}\left(\mathrm{I}_{2} \mathrm{O}_{2} \cdot \mathrm{H}_{2} \mathrm{O}\right)
$$

which claims at its turn the iodide ion. The source of iodide ions considering the dissolved iodine is the hydrolysis:

$$
\mathrm{I}_{2}+\mathrm{H}_{2} \mathrm{O} \rightleftharpoons \mathrm{H}^{+}+\mathrm{I}^{-}+\mathrm{HIO}
$$

Although the presence of this dioxide was not experimentally confirmed, it could explain the cubic utocatalysis from Brusselator assuming the following steps:

$$
\begin{gathered}
\mathrm{H}_{2} \mathrm{I}_{2} \mathrm{O}_{3}+\mathrm{HIO}_{2} \rightleftharpoons \mathrm{H}_{3} \mathrm{I}_{3} \mathrm{O}_{5} \\
\mathrm{H}_{3} \mathrm{I}_{3} \mathrm{O}_{5}+\mathrm{H}_{2} \mathrm{O}_{2} \longrightarrow 3 \cdot \mathrm{HIO}_{2}+\mathrm{H}_{2} \mathrm{O}
\end{gathered}
$$

Iodide's existence in BL systems was experimentally confirmed by Liebhafsky in 1932, so further reactions with this ion should be considered. One is the so-called Dushman reaction (known since 1904):

$$
\mathrm{IO}_{3}^{-}+5 \cdot \mathrm{I}^{-}+6 \cdot \mathrm{H}^{+} \longrightarrow 3 \cdot \mathrm{I}_{2}+3 \cdot \mathrm{H}_{2} \mathrm{O}
$$

which is able to re-enter the dissolved iodine in $\mathrm{BL}$ model (Furuichi et al., 1973).

In later works (Liebhafsky and Wu, 1974; Furuichi et al., 1975) other ionic steps were added in BL model (heterolysis of dissolved iodine, together with various oxidations and reductions of iodine acids with $\mathrm{H}_{2} \mathrm{O}_{2}$ ). Let us consider an "ionic model" one which contains electrically nonbalanced steps. Many intermediates are at least improbable in our opinion $\left(\mathrm{IO}^{-}, \mathrm{I}_{3}^{-}, \mathrm{H}_{2} \mathrm{IO}^{+}\right.$).

Another way of modelling is to consider among ionic steps, some radicalic ones (Sharma and Noyes, 1975; 1976), involving homolysis of iodine (Edelson and Noyes, 1979; Ganapathisubramanian and Noyes, 1981). Also, some physical steps, like desorption equilibrium of oxygen (Odutola et al., 1982; Treindl and Noyes, 1993) were introduced later in BL model. A radicalic model contains free radicals in some steps, but these intermediates are not verified.

Without assuming ionic or radicalic steps, a recent model called Braylator was proposed (Schmitz, 1991). It contains iodine between intermediates, among iodide and lower acids and has an autoinhibition in fifth step:

$$
\begin{gathered}
\mathrm{HIO}_{3}+\mathrm{HI} \stackrel{1}{\longrightarrow} \mathrm{HIO}+\mathrm{HIO}_{2} \\
\mathrm{HI}+\mathrm{HIO}_{2} \stackrel{2}{\longrightarrow} 2 \cdot \mathrm{HIO} \\
\mathrm{HI}+\mathrm{HIO} \stackrel{3}{\longrightarrow} \mathrm{I}_{2}+\mathrm{H}_{2} \mathrm{O} \\
\mathrm{H}_{2} \mathrm{O}_{2}+\mathrm{HIO} \stackrel{4}{\longrightarrow} \mathrm{HI}+\mathrm{H}_{2} \mathrm{O}+\mathrm{O}_{2} \\
\mathrm{H}_{2} \mathrm{O}_{2}+2 \cdot \mathrm{HIO} \stackrel{5}{\longrightarrow} \mathrm{HIO}+\mathrm{HIO}_{2}+\mathrm{H}_{2} \mathrm{O}
\end{gathered}
$$

Another iodine oxide taken into account was $\mathrm{I}_{2} \mathrm{O}$ (Schmitz, 1987) due to its similarity with existing halogen oxides $\left(\mathrm{F}_{2} \mathrm{O}\right.$ and $\left.\mathrm{Cl}_{2} \mathrm{O}\right)$. It was mentioned 
for the first time earlier (Schmitz and Rooze, 1979). It was used to insert a delay in second step of model (10) according with:

$$
\begin{aligned}
& \mathrm{HI}+\mathrm{HIO}_{2} \rightleftharpoons \mathrm{I}_{2} \mathrm{O}+\mathrm{H}_{2} \mathrm{O} \\
& \mathrm{I}_{2} \mathrm{O}+\mathrm{H}_{2} \mathrm{O} \longrightarrow 2 \cdot \mathrm{HIO}
\end{aligned}
$$

While the autoinhibition could be also eliminated by using it - i.e., by replacing reaction (12) in fifth step of (10) and reducing water in both sides. This could be done by considering reaction (12) at equilibrium instead of reaction (11).

Thus the Braylator contains six steps and has six intermediates, only one being debatable (the oxide). All steps are redox ones and the iodide gains a special role by replacing the hydrogen peroxide in some steps:

$$
\begin{aligned}
\mathrm{IO}_{3}^{-}+\mathrm{I}^{-}+2 \cdot \mathrm{H}^{+} \stackrel{1}{\longrightarrow} \mathrm{HIO}+\mathrm{HIO}_{2} \\
\mathrm{HIO}_{2}+\mathrm{I}^{-}+\mathrm{H}^{+} \stackrel{2}{\longrightarrow} \mathrm{I}_{2} \mathrm{O}+\mathrm{H}_{2} \mathrm{O} \\
\mathrm{I}_{2} \mathrm{O}+\mathrm{H}_{2} \mathrm{O} \stackrel{3}{\longrightarrow} 2 \cdot \mathrm{HIO} \\
\mathrm{HIO}+\mathrm{I}^{-}+\mathrm{H}^{+} \stackrel{4}{\longrightarrow} \mathrm{I}_{2}+\mathrm{H}_{2} \mathrm{O} \\
\mathrm{H}_{2} \mathrm{O}_{2}+\mathrm{HIO} \stackrel{5}{\longrightarrow} \mathrm{H}^{+}+\mathrm{I}^{-}+\mathrm{H}_{2} \mathrm{O}+\mathrm{O}_{2} \\
\mathrm{H}_{2} \mathrm{O}_{2}+\mathrm{I}_{2} \mathrm{O} \stackrel{6}{\longrightarrow} \mathrm{HIO}+\mathrm{HIO}_{2}
\end{aligned}
$$

These steps (the first, third and fourth being reversible) are the so-called "basic set" of reactions (also known as Schmitz model). It was found to be very promising in BL modelling (Schmitz, 1984). The acidity was written apart because it will be considered a separate species (see below).

Further studies (Kolar-Anic and Schmitz, 1992; Kolar-Anic et al., 1990a,b; Misljenovic and KolarAnic, 1990; Anic et al., 1991) have proposed and analyzed other two steps with hydrogen peroxide to complete the model (let us consider that all models involving $\mathrm{I}_{2} \mathrm{O}$ are Braylator's variants):

$$
\begin{aligned}
\mathrm{H}_{2} \mathrm{O}_{2}+\mathrm{HIO}_{2} \stackrel{7}{\longrightarrow} \mathrm{H}^{+}+\mathrm{IO}_{3}^{-}+\mathrm{H}_{2} \mathrm{O} \\
\mathrm{H}_{2} \mathrm{O}_{2}+\mathrm{IO}_{3}^{-}+\mathrm{H}^{+} \stackrel{8}{\longrightarrow} \mathrm{HIO}_{2}+\mathrm{H}_{2} \mathrm{O}+\mathrm{O}_{2}
\end{aligned}
$$

the last one together with a complex kinetic (with respect to acidity) proposed by Liebhafsky in 1933 . The same kinetic was assumed for the fifth step of (13) due to its similarity (oxygen production). Recent works (Kolar-Anic et al., 1994; 1996) were dedicated to reduce the model. The results of simulation were found to be acceptable without some steps.

One could say that Braylator seems to be simple and versatile (but strength and consistent), with stoichiometric steps. It contains credible reactions and intermediates and was adopted to be tested against our data, previously reported (Vîlcu et al., 1998). In our opinion, reactions (14) are not necessary to model the recorded damped oscillations.

\section{MODELLING CHEMICAL OSCILLATIONS}

A huge literature is dedicated to this subject (Degn, 1972; Field, 1972; Frank, 1978; Gurel and Gurel, 1983a,b and references therein). Some general aspects should be mentioned at this point. Chemical oscillations are "exotic" phenomena, with many variables. Many experiments were conducted as isothermal (and isobaric) ones. Although some temperatures were measured during the time, almost all the proposed models for BL system are purely kinetic, as for others homogeneous oscillators (Belousov-Zhabotinskii, BriggsRauscher, Hafke-Gilles, Jenson). According to this assumption, many researchers studied the possibilities of this kind of models to reproduce experimental oscillations (De Kepper, 1977; Pacault, 1977; 1979; Boissonade, 1980; Vidal and Pacault, 1982). These studies of ancient models coupled with some mathematical background have shown that few aspects are common for each oscillating reaction (or system).

From a chemical point of view, an oscillating reaction takes place in a system containing at least two central elements with three (or more) possible oxidation states (Noyes, 1980; 1990). The mechanism should contain at least two alternate ways (or paths) of reaction (Frank, 1980) which must interfere somehow (competition) or communicate 
via a key species (an intermediate in most cases). Because of mathematical requirements, at least one step will contain an amplification (autocatalysis or autoinhibition). Of course, a step involving an autocatalysis seems to be too complex, so it could be further decomposed in more elementary steps. The mathematical requirement invoked is to have at least one cubic equation in the differential system of evolution (Glansdorff and Prigogine, 1971; Glansdorff, 1979; Nicolis and Prigogine, 1977; Haken, 1977; 1978).

One way to simulate an autocatalysis was found to be (Epstein, 1984) the insertion of a delay induced by a special intermediate as earlier in Oregonator. This intermediate could be the "key" one (see above) or not, and furthermore could be a measurable or hypothetical species. Other way is to consider some different time scales for one branch of the mechanism, as in autocatalator (Gray and Scott, 1990). A different time scale could be obtained considering a slow reaction step or some delays induced by physical steps (non-ideal flow, non-ideal mixing, thermal activation, absorption equilibria - see Razon and Schmitz, 1987).

Because of the complex behavior of oscillating systems (especially when these systems are closed and oscillations are damped), models' performances should be reconsidered. For example, in the very well known case of two consecutive reactions of first order:

$$
\mathrm{A} \longrightarrow \mathrm{B} \longrightarrow \mathrm{C}
$$

the time evolution of B concentration has already four parameters: amplitude and time-position of the maximum, among with the position of inflexion points on the two branches. If one try to model a chemical system considering three or four intermediate species, these parameters are multiplied. The number of variables increases very much when some oscillations appear on one or both branches of some evolutions. These are: oscillating domain's ignition and damping related to the maximum concentration, number, amplitude and period of oscillations, the style of damping (suddenly or in a long time), etc.
It could be concluded that a good model could contain weak points (as few as possible) like hypothetical species and hypothetical steps. The model should be able to approach qualitatively the observed oscillations and remain self-consistent. Of course, it is better when the model is simple but strong and also versatile (especially with respect to temperature, via some kinetic constants). Nevertheless, self-consistency means in our opinion that some weak hypotheses remain the same during all evolutions of process. Any quantitative interpretation remains always in the stage of proposition, a slightly modification in order to fit other set of data being possible.

Let us review the major contributions in modelling $\mathrm{BL}$ reaction from these points of view (further considerations were not known at the time or, however, were not so clear). The decomposition of hydrogen peroxide (1) is catalyzed by iodic acid with the proved existence of dissolved iodine. Two chemical elements with at least three possible oxidation states are present so far (iodine and oxygen). First model assumes a redox which has two alternate branches (2) and (3), but the transition between iodic acid and iodine is too abrupt and the third oxidation state of iodine is not present. Further decomposition of each branch are necessary, together with some delay in oxygen production (according to Degn, 1967). It is obvious that the Brusselator (designed special for BL reaction) gains almost everything: four steps (two for each branch), two more intermediates with iodine in various oxidation states, a cubic autocatalysis (required for limit cycles). The major disadvantage is the lack of iodine, a verified intermediate. More steps should be involved to explain the autocatalysis. On the other hand, the new intermediates are known substances and their appearance is very consistent in BL systems.

In order to refine the model, at least a hypothetical species should be included. This could be a free radical (according to Degn, 1967). This assumption was exploited by Noyes and his coworkers. Another possibility is to consider an oxide $\left(\mathrm{I}_{2} \mathrm{O}_{2}\right.$, like Liebhafsky, which could justify the autocatalytic 
step from Brusselator, or $\mathrm{I}_{2} \mathrm{O}$, like Schmitz, which has the advantage that it does not propose an odd oxidation state for iodine).

At this point, it should be mentioned that both ways contain, first of all, the iodide, experimentally confirmed. A supplementary oxidation state for iodine and, moreover, the re-enter of dissolved iodine are major advantages, among with a step which could not be neglected anymore: the hydrolysis of iodine. This is an example of the claimed self-consistency: the existence of both iodine and iodide being confirmed, the hydrolysis seems to be justified from both sides.

The earlier form of Braylator was developed with hydrolysis and without oxide (10). It is interesting that last step contains now an autoinhibition instead of autocatalysis. The oxide $\left(\mathrm{I}_{2} \mathrm{O}\right)$ was introduced later, in order to eliminate the autoinhibition and to enter a delay in fourth step of (10) - the redox between $\mathrm{HI}$ and $\mathrm{HIO}_{2}$. Also, one could say that iodide became a key intermediate, because it substitutes hydrogen peroxide in some reducing steps. $\mathrm{H}_{2} \mathrm{O}_{2}$ remains amphoteric.

\section{TESTING OF BRAYLATOR AGAINST OUR DATA}

First, let us emphasize that all models derived from Braylator have another weak point, not so evident until one try to use them: they do not start without a little amount of iodide. This fact suggests once again that iodide is the key intermediate while its presence requires a different starting mechanism. This could be the following reaction, well known since a long time (1948):

$$
\mathrm{H}_{2} \mathrm{O}_{2}+\mathrm{I}_{2} \stackrel{\mathrm{h} \nu}{\longrightarrow} 2 \cdot \mathrm{H}^{+}+2 \cdot \mathrm{I}^{-}+\mathrm{O}_{2}
$$

The reaction (16) was proposed according to some reports which sustain a certain influence of irradiation over BL system (Sharma and Noyes, 1975). Obviously, in order to reaction (16) be possible, a quantity of dissolved iodine should be already present. This requirement involves reaction (2) in the starting mechanism, reaction (9) being also possible to interfere. Iodine becomes a key intermediate too, not for oscillations but for their ignition. The result of this reasoning is obvious: the iodine's concentration should be at a different scale. This concept of scaled concentrations will be verified below.

The abilities of Braylator in his basic form (10) were tested, assuming the possibility of slight modifications in some kinetic parameters (i.e., with at most a half of an order in magnitude). Of course, all modifications should be done only in steps containing the hypothetical intermediate $\mathrm{I}_{2} \mathrm{O}$, because the other parameters were confirmed earlier, by studying each step alone.

The starting point of simulations is the parameters' set given by Kolar-Anic and Schmitz in 1992 (without seventh step, neglected). The purpose is to fit the general aspect of recorded evolution in typical experiments (see Figure 1 in Vîlcu et al., 1998). This could be obtained with only one change: parameter $k_{2}$ should be reduced four times to get the evolution shown in Fig. 1 (all kinetic parameters are mentioned). The domain of initial concentrations is given in part I of this work; to obtain the profile of Fig. 1, initial condition should be as follows: $\left[\mathrm{IO}_{3}^{-}\right]_{0}=0.046 \mathrm{M} ;\left[\mathrm{H}^{+}\right]_{0}=0.15 \mathrm{M} ;\left[\mathrm{H}_{2} \mathrm{O}_{2}\right]_{0}=$ $0.2275 \mathrm{M} ;\left[\mathrm{I}^{-}\right]_{0}=10^{-10} \mathrm{M}$. The last value stands to approximate the required non-zero iodide concentration (see above).

A qualitative analysis of Fig. 1 compared with reported observations show a good correspondence for maximum value of iodine concentration and for oscillations' amplitudes. Few differences still exist: a certain delay in the occurrence of the maximum, the absence of any chaotic period and a bigger oscillatory domain.

First consistency test is related to concentration scales. A larger amount of initial iodide blocks the oscillations, so this is the key (i.e., the most sensitive) intermediate. The other intermediates are either at the same scale ( $\mathrm{HIO}$ and $\mathrm{HIO}_{2}$ ) or at different ones: according with previous assumptions, the dissolved iodine stands always at higher values of concentrations (being pre-existent) while 


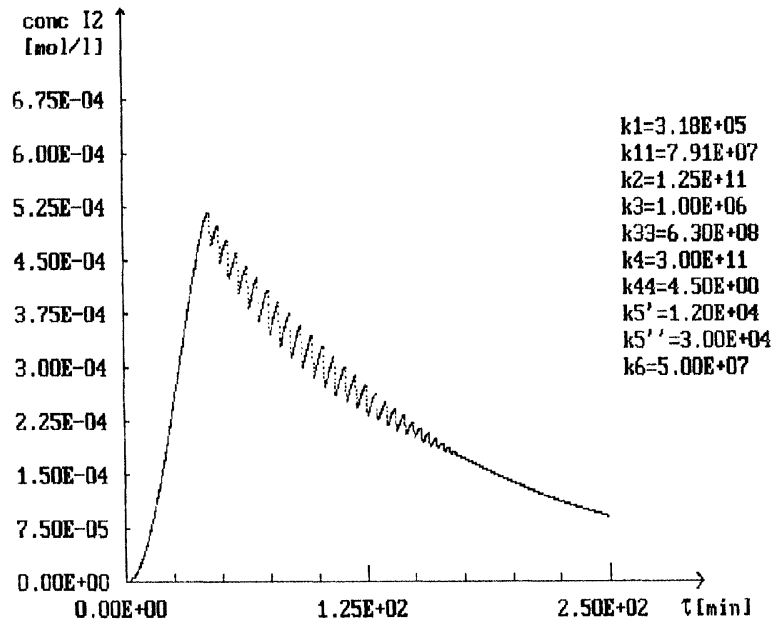

FIGURE 1 Simulated time-evolution of iodine concentration.

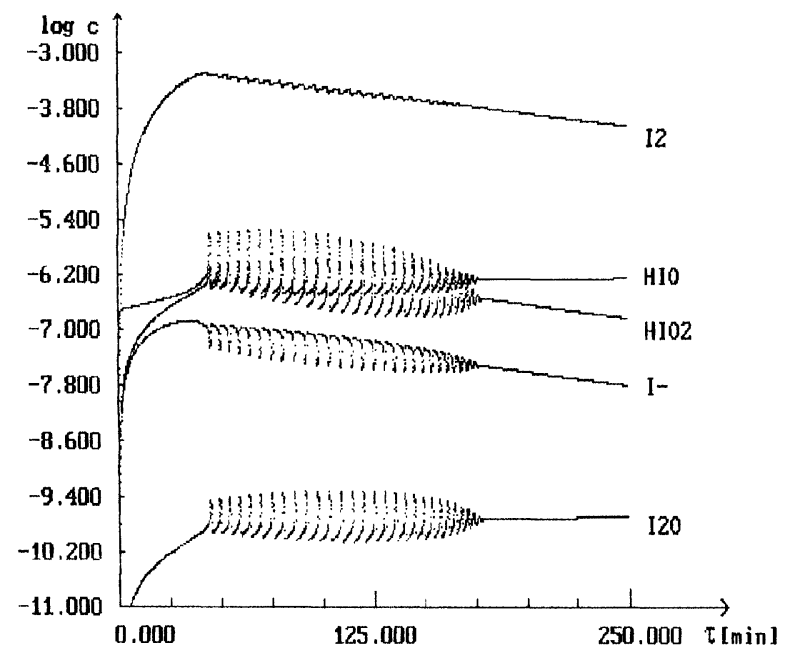

FIGURE 2 Concentration scales for BL intermediates.

the presumed "almost null" concentration of the hypothetical oxide is confirmed (see Fig. 2).

Another challenge for this model is to reproduce the behaviour of BL system when initial concentrations change. The simulations with a smaller acidity $(0.1 \mathrm{M})$ and with a smaller $(0.0725 \mathrm{M})$ or bigger $(0.5 \mathrm{M})$ concentration of peroxide show an agreement with the experiment. Once again, the model seems to be self-consistent: oscillations disappear at critical values of these concentrations while their aspect depends in the same manner on the initial composition. The oscillatory domain is delayed with increasing of peroxide initial concentration and the oscillations become slower (longer in period and bigger in amplitude) with decreasing of initial acidity. The number of oscillations decreases with acidity increasing and both changes of peroxide concentration while the entire oscillatory domain is shorter when concentration of peroxide decreases or acidity increases.

In order to eliminate the delay in maximum's appearance, a very simple idea arises: a different starting mechanism being already presumed, this could also accumulate some dissolved iodine, so when the BL system switches to Braylator, it starts with an initial concentration of iodine (non-zero). For example, with $\left[\mathrm{I}_{2}\right]_{0}=5 \cdot 10^{-4} \mathrm{M}$, the delay disappears and a very short synchronization appears instead (which could be further assimilated with a chaotic domain).

The different scenario preceding the Braylator consists of reaction (2) which generate the iodine and should contain at least one step which generate iodide, in order that Braylator could start. Two alternatives could be considered: the hydrolysis (6) and the photochemical redox (16). Also, Dushman reaction (9) should be taken into account because it could serve as a regulator of iodine-iodide equilibrium. According with observed behaviours, the switching to Braylator could take place at high concentration of iodine and low concentration of iodide, the oscillating domain which follows being characterized by fast oscillations (see above) and beginning with a sharp maximum. Otherwise, the switching takes place at high concentration of iodide and low concentration of iodine and the oscillations are slow and small, after a delayed and little maximum of iodine concentration. This kind of oscillations could be reinitiated by dilution while the other could not.

The last step in BL modelling is to take into account the influence of temperature, especially the thermal activation already reported. In order to remain isothermal, the Braylator should not be very affected by temperature's change. On the other 
hand, thermal activation could be transferred in the starting mechanism. Further verifications being necessary, at this time let us propose an activation energy for Dushman reaction of $5-10 \mathrm{kcal} / \mathrm{mol}$. This value could be estimated using an indirect calculus: between experimental temperatures (333$363 \mathrm{~K}$ ), the modifications induced in kinetic parameters are very small (below four times). Meanwhile, other concurrent reactions should have an activation energy below $1 \mathrm{kcal} / \mathrm{mol}$. In order to have an ignition point (a critical temperature), the mechanism of Dushman reaction is expected to be much complex, but a seperate experiment is impossible for the moment.

The major result of this work is that assuming a starting mechanism, no physical influences should be considered. Being so sensitive to the temperature, it seems more appropriate to say that irradiation could affect BL system by heating, so it is not necessary to consider free radicals involved. Also, our experiments have shown that stirring is not necessary; furthermore, the evolving oxygen could be considered to play a role in mixing, because the chaotic perid is shorter at high temperatures.

\section{References}

Anic, S., Kolar-Anic, L., Stanisavljev, D., Begovic, N. and Mitic, D. (1991). Dilution reinitiated oscillations in the BrayLiebhafsky system. React. Kinet. Catal. Lett. 43, 155-162.

Boissonade, J. (1980). Non-linear dynamics and fluctuations in non-equilibrium chemical systems. Ph.D. Thesis, Bordeaux.

Degn, H. (1967). Evidence of a branched chain reaction in the oscillating reaction of hydrogen peroxide, iodine and iodate. Acta Chem. Scand. 21, 1057-1066.

Degn, H. (1972). Oscillating chemical reactions in homogenous phase. J. Chem. Education 49, 302-306.

De Kepper, P. (1977). Contributions a l'étude expérimentale de systèmes dissipatifs chimiques: Réactions oscillantes de Briggs-Rauscher et de Belousov-Zhabotinskii. Ph.D. Thesis, Bordeaux.

Edelson, D. and Noyes, R.M. (1979). Detailed calculations modelling the oscillatory Bray-Liebhafsky reaction. J. Phys. Chem. 83, 212-220.

Epstein, I.R. (1984). The search of new chemical oscillators. In Chemical Instabilities (NATO ASI Series, C 120, G. Nicolis and F. Baras, Eds.), D. Reidel Publishing Comp., Dordrecht, pp. 3-18.

Field, R.J. (1972). A reaction periodic in time and space. J. Chem. Education 49, 308-311.

Franck, U.F. (1978). Chemical oscillations. Angew. Chem. Int. Ed. Engl. 17, 1-15.
Franck, U.F. (1980). Feedback kinetics in physiochemical oscillations. Ber. Bunsenges. Phys. Chem. 84, 334-341.

Furuichi, R. and Liebhafsky, H.A. (1973). Radioactive iodine exchange and the Dushman reaction. Bull. Chem. Soc. Japan 46, 2008-2010.

Furuichi, R. and Liebhafsky, H.A. (1975). Rate of the Dushman reaction in iodic acid at low iodide concentration. Complexity of iodic acid. Bull. Chem. Soc. Japan 48, 745-750.

Ganapathisubramanian, N. and Noyes, R.M. (1981). Oscillatory oxygen evolution during catalyzed disproportionation of hydrogen peroxide. J. Phys. Chem. 85, 1103-1105.

Glansdorff, P. and Prigogine, I. (1971). Structure, Stabilité et Fluctuations. Masson et $\mathrm{C}^{\mathrm{ie}}$, Paris.

Glansdorff, P. (1979). Origine et perspectives des structures disipatives. In Synergetics, Far from Equilibrium (Springer Series in Synergetics 3, A. Pacault and C. Vidal, Eds.), SpringerVerlag, Berlin, Heidelberg, New York, Tokyo, pp. 1-11.

Gray, P. and Scott, S.K. (1990). Chemical Oscillations and Instabilities. Oxford Science Publication, Clarendon Press, Oxford.

Gurel, O. and Gurel, D. (1983a). Types of Oscillations in Chemical Reactions. Springer-Verlag, Berlin, Heidelberg, New York, Tokyo.

Gurel, D. and Gurel, O. (1983b). Recent Developments in Chemical Oscillations. Springer-Verlag, Berlin, Heidelberg, New York, Tokyo.

Haken, H. (1977). Some aspects of synergetics. In Synergetics, A Workshop (Springer Series in Synergetics 2, H. Haken, Ed.), Springer-Verlag, Berlin, Heidelberg, New York, pp. 2-17.

Haken, H. (1978). Synergetics, An Introduction - Non-equilibrium Phase Transitions and Self-organization in Physics, Chemistry and Biology (Springer Series in Synergetics 1). Second Edition, Springer-Verlag, Berlin, Heidelberg, New York.

Kolar-Anic, L.Z., Misljenovic, D.M., Stanisavljev, D.R. and Anic, S.R. (1990a). Applicability of Schmitz's model to dilution-reinitiated oscillations in the Bray-Liebhafsky reaction. J. Phys. Chem. 94, 8144-8146.

Kolar-Anic, L., Stanisavljev, D., Krnajski Belovjev, G., Peeters, P. and Anic, S. (1990b). The first maximum of the iodide concentration in the Bray-Liebhafsky reaction. Computers Chem. 14, 345-347.

Kolar-Anic, L. and Schmitz, G. (1992). Mechanism of the BrayLiebhafsky reaction: Effect of the oxidation of iodous acid by hydrogen peroxide. J. Chem. Soc., Faraday Trans. 88, $2343-2349$

Kolar-Anic, L., Misljenovic, D. and Anic, S. (1994). Modelling of Bray-Liebhafsky Process. The theoretical analysis of the role of the reaction $\mathrm{IO}_{3}^{-}+\mathrm{I}^{-}+2 \cdot \mathrm{H}^{+} \rightleftharpoons \mathrm{HIO}+\mathrm{HIO}_{2}$. In Dynamics Days, 15th Annual Informal Workshop, Budapest, pp. 1-9.

Kolar-Anic, L., Misljenovic, D., Anic, S. and Nicolis, G. (1996). The influence of the reduction of iodate ion by hydrogen peroxide on the model of the Bray-Liebhafsky reaction. React. Kinet. Catal. Lett., preprint.

Liebhafsky, H.A. and Wu, L.S. (1974). Reactions involving hydrogen peroxide, iodine and iodate ion. V. Introduction to the oscillatory decomposition of hydrogen peroxide. J. Am. Chem. Soc. 96, 7180-7187.

Matsuzaki, I., Simic, R. and Liebhafsky, H.A. (1972). The mechanism of decomposition of hydrogen peroxide by iodine in acid solutions. The rates of asscoiated reactions. Bull. Chem. Soc. Japan 45, 3367-3371.

Misljenovic, D.M. and Kolar-Anic, L. (1990). First integral method for evaluation of the relations between components of Bray-Liebhafsky models. Croatica Chem. Acta 63, 693-699. 
Nicolis, G. and Prigogine, I. (1977). Self-organization in Nonequilibrium Systems. Wiley-Interscience, New York.

Noyes, R.M. (1980). Effects of global constraints on permissible local behavior. Ber. Bunsenges. Phys. Chem. 84, 295-303.

Noyes, R.M. (1990). The current state of chemical oscillators. React. Kinet. Catal. Lett. 42, 169-180.

Odutola, J.A., Bohlander, C.A. and Noyes, R.M. (1982). Chemical oscillations and instabilities. 46. Iodide ion measurements on the oscillatory iodate-peroxide system. J. Phys. Chem. 86, 818-824.

Olsen, L.F. (1984). The enzyme and the strange attractor Comparisons of experimental and numerical data for an enzyme reaction with chaotic motion. In Stochastic Phenomena and Chaotic Behaviour in Complex Systems (Springer Series in Synergetics 21, P. Schuster, Ed.), Springer-Verlag, Berlin, Heidelberg, New York, Tokyo, pp. 116-123.

Pacault, A. (1977). Chemical evolution far from equilibrium. In Synergetics, A Workshop (Springer Series in Synergetics 2, H. Haken, Ed.), Springer-Verlag, Berlin, Heidelberg, New York, pp. 133-154.

Pacault, A. (1979). Evolution chimique loin de l'équilibre: concepts, modeles et réel. In Synergetics, Far from Equilibrium (Springer Series in Synergetics 3, A. Pacault and C. Vidal, Eds.), Springer-Verlag, Berlin, Heidelberg, New York, pp. $128-146$.

Razon, L.F. and Schmitz, R.A. (1987). Multiplicities and Instabilities in Chemically Reacting Systems - A Review. Chem. Eng. Sci. 42, 1005-1047.

Schmitz, G. and Rooze, H. (1979). Etude cinétique de la réaction de Bray. In Synergetics, Far from Equilibrium (Springer Series in Synergetics 3, A. Pacault and C. Vidal, Eds.), SpringerVerlag, Berlin, Heidelberg, New York, Tokyo, pp. 51-56.

Schmitz, G. (1984). Mécanisme de la Réaction de Bray. In NonEquilibrium Dynamics in Chemical Systems (Springer Series in Synergetics 27, C. Vidal and A. Pacault, Eds.), SpringerVerlag, Berlin, Heidelberg, New York, Tokyo, p. 237.

Schmitz, G. (1987). Cinétique de la réaction de Bray. J. Chim. Phys. 84, 957-965.

Schmitz, G. (1991). Etude du Braylator par la méthode de Clarke. J. Chim. Phys. 88, 15-25.

Sharma, K.R. and Noyes, R.M. (1975). Oscillations in chemical systems. VII. Effects of light and of oxygen on the BrayLiebhafsky reaction. J. Am. Chem. Soc. 97, 202-204.

Sharma, K.R. and Noyes, R.M. (1976). Oscillations in chemical systems. 13. A detailed molecular mechanism for the BrayLiebhafsky reaction of iodate and hydrogen peroxide. J. Am. Chem. Soc. 98, 4345-4361.

Treindl, L. and Noyes, R.M. (1993). A new explanation of the oscillations in the Bray-Liebhafsky reaction. J. Phys. Chem. 97, $11354-11362$.

Vîlcu, R., Danciu, T. and Bala, D. (1998). The study of BrayLiebhafsky reaction over a wide range of temperatures. I. Experimental contributions. Discrete Dynamics in Nature and Society, 2, 195-201.

Vidal, C. and Pacault, A. (1982). Spatial chemical structures, chemical waves. A review. In Evolution of Order and Chaos in Physics, Chemistry and Biology (Springer Series in Synergetics 17, H. Haken, Ed.), Springer-Verlag, Berlin, Hiedelberg, New York, pp. 74-99. 


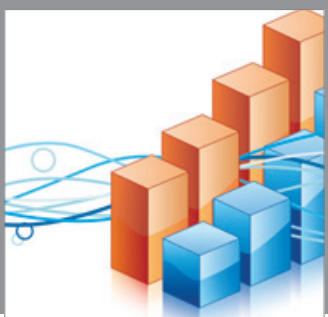

Advances in

Operations Research

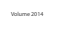

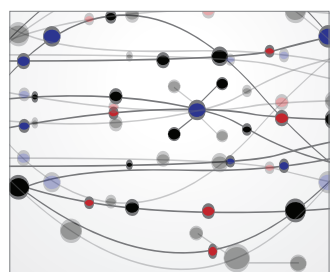

\section{The Scientific} World Journal
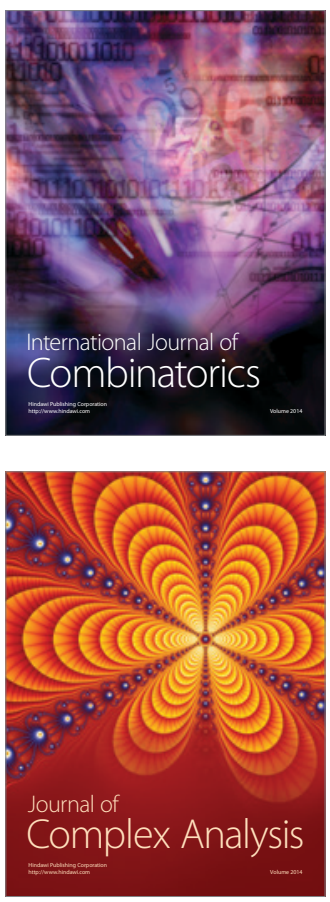

International Journal of

Mathematics and

Mathematical

Sciences
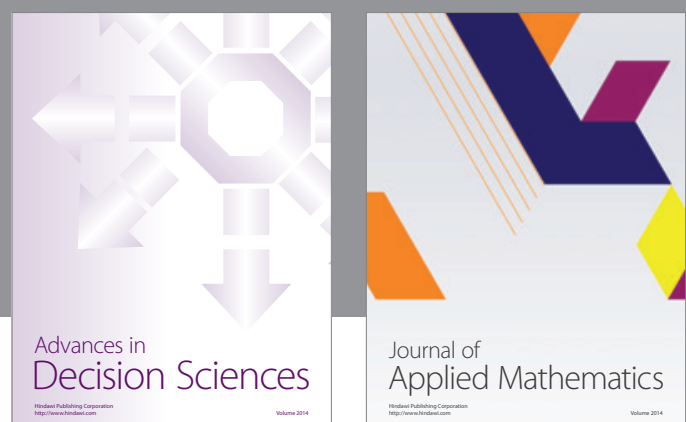

Journal of

Applied Mathematics
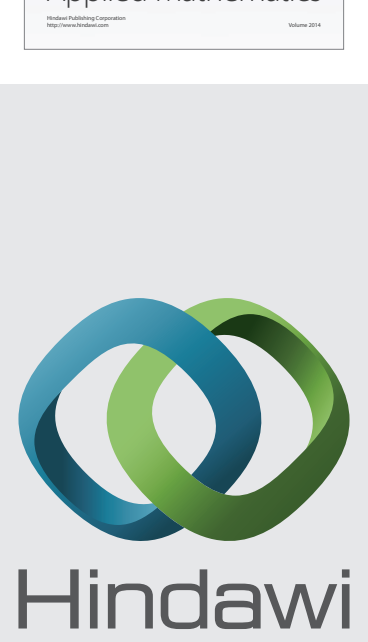

Submit your manuscripts at http://www.hindawi.com
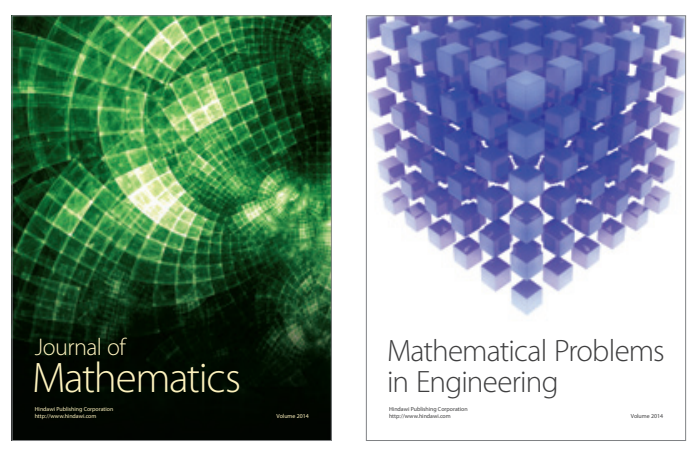

Mathematical Problems in Engineering
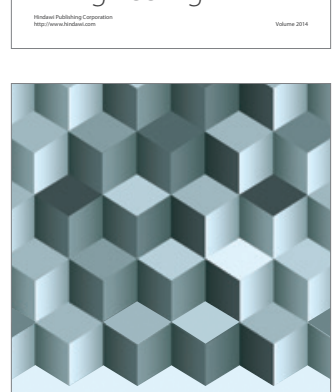

Journal of

Function Spaces
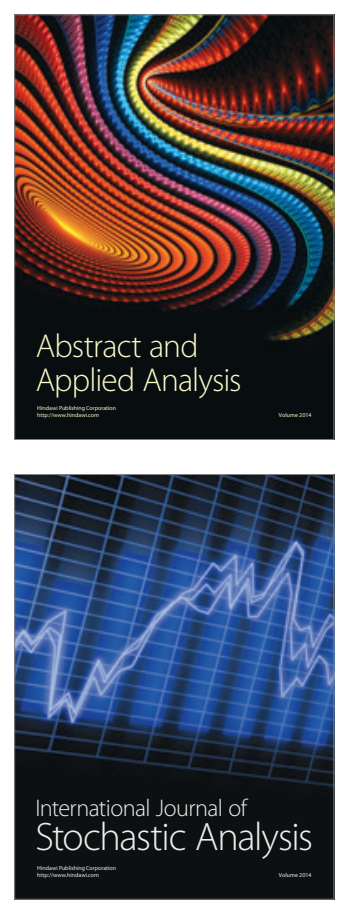

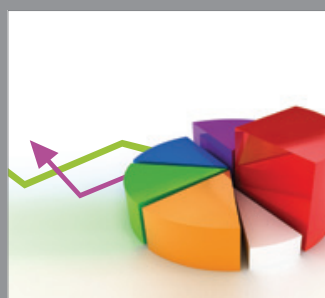

ournal of

Probability and Statistics

Promensencen
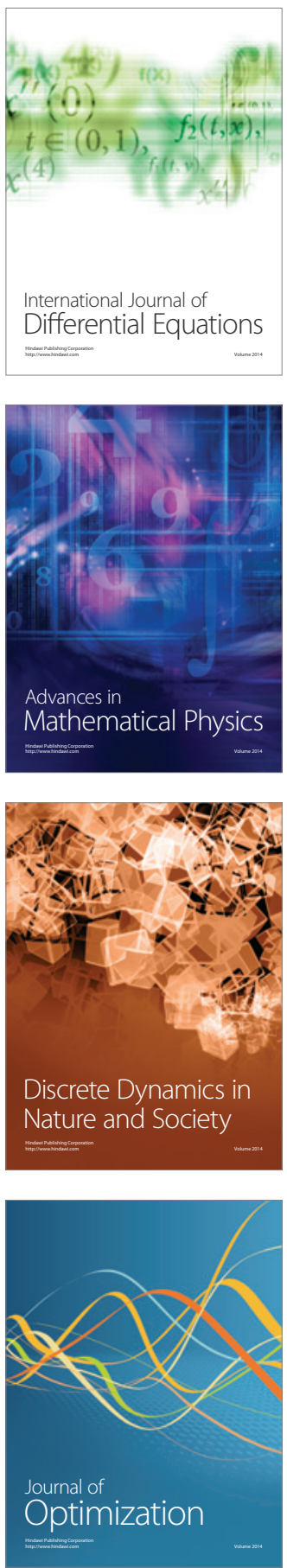